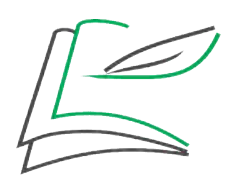

Entretextos

Entretextos 20(2):59-78;jul./dez. 2020

ISSN 1519-5392

$10.5433 / 1519-5392.2020 v 21 n 2 p 59$

\title{
Oralidade nas aulas de língua portuguesa: um diagnóstico do problema frente à Base Nacional Comum Curricular
}

\author{
Orality in Portuguese language teaching: a diagnosis of the problem \\ considering the National Curricular Common Basis
}

La oralidad en las clases de portugués: un diagnóstico del problema junto a la Base Nacional Común Curricular

\author{
Cinara Sousa da Silva ${ }^{1}$ (iD https://orcid.org/0000-0003-2891-8780 \\ Adelino Pereira dos Santos ${ }^{2}$ (iD) https://orcid.org/0000-0001-9920-3649 \\ Lícia Maria Bahia Heine ${ }^{3}$ (iD https://orcid.org/0000-0001-9100-7547
}

\begin{abstract}
RESUMO: Neste artigo, apresentamos parte de uma pesquisa desenvolvida como diagnóstico sobre competências e habilidades no desempenho de gêneros discursivos orais formais, de alunos do oitavo ano do ensino fundamental, em uma escola pública de um município do baixo sul da Bahia, como desenvolvimento do Mestrado Profissional em Letras, realizado por uma das autoras deste artigo. $\mathrm{O}$ objetivo desta parte do trabalho de pesquisa foi analisar as habilidades referentes ao gênero discursivo oral seminário, a partir de transcrições das apresentações, como exemplos, feitas pela professora-pesquisadora. A análise dos dados permitiu concluir que cinco dos onze conteúdos relacionados ao seminário não foram identificados nas apresentações dos discentes, apenas três deles foram demonstrados pelos alunos na íntegra e os outros três apenas parcialmente. Dos questionamentos, suscitados a princípio, obtivemos a seguinte constatação: existem características/ conteúdos que somente alguns alunos conseguem demonstrar, sobre o gênero discursivo seminário, devido à sua prática mais frequente. Por isso, os conteúdos dos gêneros discursivos orais, sua estrutura, modos de funcionamento e características linguísticas e textuais precisam ser formalmente ensinados, para que sejam realizados com constância e conscientemente.
\end{abstract}

PALAVRAS-CHAVE: Oralidade. Gêneros discursivos orais. Seminário.

\footnotetext{
${ }^{1}$ Mestre em Letras. Professora de Língua Portuguesa da Educação Básica pela SEC/BA. Secretaria de Educação do Estado da Bahia - SEC/BA. E-mail: cinara sousa@hotmail.com

2 Doutor em Letras. Professor titular do Departamento de Ciências Humanas do Campus $V$ da Universidade do Estado da Bahia. E-mail: adesantos@uneb.br

${ }^{3}$ Doutora em Letras. Professora titular do Instituto de Letras da Universidade Federal da Bahia. E-mail: liciaheine@uol.com.br
} 
ABSTRACT: In this article, we present part of a research developed as an initial diagnosis about competences and abilities in the performance of formal oral discursive genres of eighth grade students in a public school in a municipality in the lower south of Bahia, development of a Professional Master in Language Teaching, conducted by one of the authors of this article. Thegenre seminar, from transcriptions of the presentations, as examples, made by the teacher-researcher. The analysis of the data allowed to conclude that five of the eleven contents related to the seminar were not identified in the presentations of the students, only three of them were demonstrated by the students in their entirety and the other three only partially. From the questioning, raised at first, we have the following statement: there are characteristics / contents that only some students can demonstrate, about the discursive genre seminar, due to its more frequent practice. Therefore, the contents of oral discursive genres, their structure, modes of functioning and linguistic and textual characteristics need to be formally taught, to be carried out consistently and consciously.

KEYWORDS: Orality. Oral discursive genres. Seminar.

RESUMEN: En este articulo, presentamos parte de una investigación desarrollada como diagnóstico sobre competencias y habilidades en el desempeño de géneros discursivos orales formales, de alumnos del octavo año de la enseñanza fundamental, en una escuela pública de un municipio del bajo sur de Bahía, como desarrollo del curso de Maestría Profesional en Letras, realizado por una de las autoras de este artículo. El objetivo de esta parte del trabajo de investigación fue analizar las habilidades referentes al género discursivo oral seminario, a partir de transcripciones de las presentaciones, como ejemplos, hechas por la profesora-investigadora. El análisis de los datos permitió concluir que cinco de los once contenidos relacionados al seminario no fueron identificados en las presentaciones de los discentes, sólo tres de ellos fueron demostrados por los alumnos en su totalidad y los otros tres sólo parcialmente. De los cuestionamientos, suscitados al principio, obtuvimos la siguiente constatación: existen características / contenidos que sólo algunos alumnos logran demostrar, sobre el género discursivo seminario, debido a su práctica más frecuente. Por lo tanto, el contenido de los géneros discursivos orales, su estructura, modos de funcionamiento y las características lingüísticas y textuales se les debe enseñar formalmente, a realizar constantemente y conscientemente.

PALABRAS CLAVE: Oralidad. Géneros discursivos orales. Seminario.

\section{Introdução}

Oralidade na sala de aula é um assunto que tem ganhado cada vez mais espaço nos debates relacionados ao ensino de Língua Portuguesa. Mesmo que lentamente, é possível verificar iniciativas em busca do fortalecimento de ações pedagógicas que tratem os gêneros orais como práticas sociodiscursivas e promovam diversas situações de uso da língua. Por muito tempo os gêneros discursivos orais ocuparam um lugar secundário no processo de ensino-aprendizagem, provavelmente devido ao equívoco de atribuírem à escrita um status superior à da fala, e essa é uma das razões que nos impulsionam à reflexão sobre a oralidade, de modo que essa modalidade da língua se constitua em um dos eixos a serem explorados de forma sistemática na sala de aula. 
Sabemos que é no cotidiano escolar que conseguimos detectar os reais problemas relacionados ao ensino da língua, que ainda perduram e dificultam o agir do professor, assim como o desenvolvimento do aluno. Um desses problemas, já mencionado, está relacionado ao pouco espaço que era dado à oralidade na sala de aula, apesar de que há mais de vinte anos documentos oficiais, como os PCNs (BRASIL, 1997), vêm exigindo do professor um trato maior com os gêneros discursivos, orais e escritos, principalmente nas aulas de Língua Portuguesa. Mais recentemente, a Base Nacional Comum Curricular (BRASIL, 2017) reiterou o que já tinha sido estabelecido pelos PCNs (BRASIL, 1997), a oralidade como um dos eixos que configuram as práticas de uso da língua, enfatizando a necessidade de propostas em que os gêneros discursivos sejam trabalhados em situações formais e informais da língua. Como se verifica na declaração a seguir:

O Eixo da Oralidade compreende as práticas de linguagem que ocorrem em situação oral com ou sem contato face a face, como aula dialogada, webconferência, mensagem gravada, spot de campanha, jingle, seminário, debate, programa de rádio, entrevista, declamação de poemas (com ou sem efeitos sonoros), peça teatral, apresentação de cantigas e canções, playlist comentada de músicas, vlog de game, contação de histórias, diferentes tipos de podcasts e vídeos, dentre outras. Envolve também a oralização de textos em situações socialmente significativas e interações e discussões envolvendo temáticas e outras dimensões linguísticas do trabalho nos diferentes campos de atuação (BRASIL, 2017, p. 76-77).

O papel da escola como instituição principal na propagação do conhecimento é incluir os gêneros discursivos orais, não só do cotidiano do aluno, mas da esfera pública, como objeto de ensino, visto que estes possuem regularidades que os tornam de difícil construção. Com isso, as propostas anteriores, organizadas nos PCNs (BRASIL, 1997), foram reformuladas no intuito de definir as bases para o fortalecimento do ensino da Língua Portuguesa e a criação de ambientes que estimulem o uso da língua, tanto escrita como oral, em suas diversas formas e graus de formalidade.

Apesar dessas orientações nos documentos referenciais, o que muitas vezes vemos como prática de sala de aula é o uso restrito da língua à modalidade escrita, com intenções voltadas apenas para a interpretação de textos e estudos gramaticais; ou ainda propostas de atividades de expressão oral que não abarcam o estudo das características dos gêneros discursivos orais em sua totalidade. Não que o professor não reconheça a importância desse trabalho com os gêneros orais, mas por serem diversos os empecilhos que, de certa forma, contribuem para que a oralidade seja posta de lado nas atividades 
Silva, C. S.; Santos, A. P.; Heine, M. B. L.

com a língua. Podemos citar a dificuldade que temos em compreender como esses gêneros se caracterizam, o que deles ensinar, como ensiná-los e, principalmente, como utilizá-los para avaliação do desempenho linguístico do aluno. Em consequência disso, lidamos com uma gama de alunos que pouco conhecem ou utilizam os gêneros discursivos orais da instância pública, pois seu domínio dos gêneros orais restringe-se ao seu cotidiano, às práticas comunicativas da esfera particular.

Neste artigo, apresentamos parte de uma pesquisa desenvolvida como diagnóstico sobre competências e habilidades na apresentação de gêneros discursivos orais da instância pública por alunos do oitavo ano do ensino fundamental, em uma escola pública de um município do baixo sul da Bahia, como parte do Mestrado Profissional em Letras, realizado por uma das autoras deste artigo. O diagnóstico como um todo se compôs por um formulário semi-estruturado, que foi preenchido por todos os alunos da turma, e da apresentação de seminários sobre temas relacionados à juventude e à política, por duas equipes, que se apresentaram para os demais colegas, sob a observação e supervisão da professora de Língua Portuguesa da turma, mestranda e autora da pesquisa. Neste trabalho, apresentamos somente o desempenho dos alunos em relação ao seminário, a partir da transcrição do evento, realizado pela docente.

Para essa parte do diagnóstico, foi considerado o seguinte questionamento, como problema de investigação: que características do gênero discursivo seminário alunos do oitavo ano do ensino fundamental já dominam, ao se apresentarem oralmente para os seus colegas, em sala de aula?

Assim sendo, o objetivo dessa parte do trabalho de pesquisa foi analisar as habilidades orais referentes ao gênero discursivo oral seminário, de alunos do oitavo ano de uma escola pública de um município do baixo sul da Bahia, a fim de, a partir do diagnóstico inicial, apresentar uma proposta de intervenção pedagógica com vista ao aperfeiçoamento de competências orais de gêneros discursivos da instância pública e o desenvolvimento de outras possíveis habilidades. A proposta de intervenção pedagógica será apresentada, detalhadamente, na dissertação de mestrado, desenvolvida por uma das autoras deste artigo e orientada por seu coautor.

Este artigo encontra-se assim organizado: nas duas primeiras seções tecemos considerações teóricas e revisão bibliográfica sobre oralidade, e sobre esse tema em documentos oficiais que direcionam o ensino de Língua Portuguesa na educação básica. Na penúltima seção, apresentamos o desempenho dos alunos, a partir das transcrições 
de partes do seminário e fazemos breve análise sobre esse desempenho. Na última seção, tecemos nossas considerações finais, reflexão sobre as habilidades que alunos do ensino fundamental necessitam desenvolver à luz do que determina a Base Nacional Comum Curricular para a prática da oralidade na educação básica.

\section{Oralidades: definições de um campo de investigação}

Quando o assunto é oralidade existem conceitos a ser definidos, a fim de que não haja confusões, principalmente no que se refere ao termo em si e às concepções que the foram atribuídas pelos estudos linguísticos e em outras áreas do conhecimento. O que se compreende por oralidade? Existem diferenças entre oralidade, fala, língua falada, gêneros discursivos orais? É possível falarmos de oralidades? Diante da dimensão que esse termo agrega, sentimos a necessidade de delimitar qual o objeto de estudo que aqui propomos discutir, ou seja, os aspectos da oralidade que serão postos em foco, para que nossos objetivos sejam bem compreendidos.

De fato, oralidade é um termo amplo, que abarca várias definições, remete e se relaciona a outros termos e foi objeto de muitos estudos ao longo da história da humanidade. Tais estudos foram impulsionados pela necessidade de ampliação dos conhecimentos referentes à língua e seu funcionamento, implementados mais sistematicamente durante o século passado ${ }^{4}$ e que se prolongam até os dias atuais.

No latim utilizava-se a expressão os para se referir à boca, que declinou para oris, de onde surgiu o vocábulo orale, deste, o termo oralidade. A palavra, em seu significado a priori, designa uma característica do que é oral, da língua falada, uma verbalização por meio sonoro. Por essa definição é possível identificarmos que o termo se refere, a grosso modo, a ação de produzir sons, utilizando a boca, sons esses que partiram de simples interjeições e onomatopeias, para a construção de enunciados mais complexos, visando primordialmente a comunicação. Definido o seu significado, resta-nos entender seu uso nas diversas áreas dos estudos sobre a língua. Marcuschi (2010) nos apresenta uma definição a respeito do que seja oralidade, a fim de distingui-la do que seja a fala. Oralidade, de maneira geral, configura-se em uma prática social, enquanto a fala caracteriza-se como uma modalidade de uso da língua. Em suas palavras:

\footnotetext{
${ }^{4}$ Referimo-nos aqui aos estudos sobre oralidade que foram implementados pela Sociolinguística, pela Linguística Textual e pela Análise da Conversação, desenvolvidos mais acentuadamente a partir da segunda metade do século passado.
} 
Silva, C. S.; Santos, A. P.; Heine, M. B. L.

A oralidade seria uma prática social interativa para fins comunicativos que se apresenta sob variadas formas ou gêneros textuais fundados na realidade sonora; ela vai desde uma realização mais informal à mais formal nos mais variados contextos de uso. [...] A fala seria uma forma de produção textualdiscursiva para fins comunicativos na modalidade oral (situa-se no plano da oralidade, portanto), sem a necessidade de uma tecnologia além do aparato disponível pelo próprio ser humano (MARCUSCHI, 2010, p. 25).

Por essa definição apresentada por Marcuschi (2010), a oralidade pode ser associada a certos aspectos da prática social de escrita, em suas diversas formas, e mais relacionada aos gêneros discursivos. No entanto, mesmo diante dessa concepção, ainda é comum verificarmos o uso restrito da palavra para definir o próprio ato da fala ou até mesmo a simples emissão da voz em situações de comunicação oral ou de leitura (oralização do texto escrito). Em outros contextos, oralidade fará menção à transmissão por meio sonoro dos conhecimentos acumulados na memória e passados de geração a geração, como a transmissão oral de mitos e lendas, dos contos de fadas etc. Há quem associe o termo ao texto oral, à linguagem verbal na modalidade oral e à língua falada ou palavra falada. Certamente, não há equívocos nessa prática e, mesmo que haja singularidades e conceituações para cada um desses termos, é incontestável a relação deles com o que podemos compreender por oralidade.

Para fins teóricos vale uma observação preliminar a respeito das definições de cada termo que se associa ao campo do oral. Como já afirmamos, oralidade é um termo cuja significação direciona-nos aos outros termos, numa relação intrínseca. Se a oralidade configura-se à prática ou ato de se comunicar, termos como fala, língua falada e modalidade oral da língua se associam e ampliam sua definição.

Em linhas gerais, de maneira simplista e até reducionista, mas para tentar compreender essa relação, quando o ser humano quer se comunicar utiliza várias estratégias caracterizadas como formas de linguagem. Caso se valha de gestos, símbolos e imagens para esse fim, estará utilizando a linguagem não-verbal; caso prefira o uso do verbo, da palavra (das mais simples expressões até as complexas), fará uso da linguagem verbal. A fala, como produção oral, se configura como instrumento para realização dessa ação de se comunicar e, por sua vez, se emoldura num código para facilitar a compreensão entre aqueles que vivem em grupos, em comunidade. A esse código chamamos de língua, sendo, portanto, a língua falada o código em sua modalidade oral. Quando essa língua se organiza em estruturas, coerentemente, maiores e mais complexas - procedimentos lexicais e gramaticais - forma-se o texto oral, 
cuja configuração variará de contexto a contexto, dependendo das necessidades e exigências da situação de comunicação, o que denominamos de gêneros discursivos orais.

É na relação do oral com o escrito que a oralidade vai sendo ampliada e que se agregam novos sentidos ao termo. Foi a partir do surgimento da escrita e de seu aparato tecnológico que esse termo foi ressignificado, fazendo referência tanto ao puramente oral, quanto ao oral produzido sob influência, direta ou indireta, da escrita. Dessa forma, não seria equívoco falar em oralidades, pois, partindo de um olhar mais apurado, Ong (1998) compreendeu a existência de dois tipos de oralidade, a primária e a secundária:

Designo como "oralidade primária" a oralidade de uma cultura totalmente desprovida de qualquer conhecimento da escrita ou da impressão. É "primária" por oposição à "oralidade secundária" da atual cultura de alta tecnologia, na qual uma nova oralidade é alimentada pelo telefone, pelo rádio, pela televisão ou por outros dispositivos eletrônicos, cuja existência e funcionamento dependem da escrita e da impressão (ONG, 1998, p. 19).

Nesse sentido, a oralidade primária está associada à cultura oral, à tradição oral e aos estudos de áreas como a etnologia; enquanto a oralidade secundária, associada à escrita, é objeto de estudo de áreas do conhecimento como a linguística. Zumthor (1993) distingue três tipos de oralidade que correspondem a três situações de cultura: uma primária e imediata que "não comporta nenhum contato com a escritura" (ZUMTHOR, 1993, p. 18) e outras duas que coexistem com ela: a oralidade mista e a oralidade segunda. A mista "quando a influência da escrita permanece externa, parcial e atrasada" e a segunda "quando se recompõe com base na escritura num meio onde esta tende a esgotar os valores da voz no uso e no imaginário" (ZUMTHOR, 1993, p. 18). Essas duas últimas especificações correlacionam a oralidade com a cultura escrita e com a cultura letrada. Ou seja, ao ampliar o sentido da escrita, ampliou-se também a definição do que poderíamos entender por oralidade. Na seção a seguir, discutimos o termo oralidade a partir da perspectiva de documentos oficiais que direcionam o ensino de língua portuguesa.

\section{Oralidade na escola: o que dizem os documentos oficiais?}

Segundo Antunes (2003), por muito tempo a educação brasileira esteve pautada nas ideologias da escola tradicional, tendo como centro a figura do professor. Este, revestido da autoridade que lhe incumbia a profissão, restringia sua prática a transmissão 
dos conteúdos a serem aprendidos pelos alunos, os quais eram as tábulas rasas que seriam preenchidas por uma gama de conhecimentos, julgados de fundamental importância pela escola. Nesse quadro não só o professor, mas o silêncio, de igual forma, compunha a pintura que representava o cotidiano da sala de aula. Alunos em fileiras, inertes, calados, intimidados pela imponente figura do professor, direcionavam sua atenção para atividades de classificação de elementos linguísticos, nomenclaturas gramaticais e redação escolar, isto é, produção de textos sem muita funcionalidade. Atividades essas que negavam as reais funções sociais da leitura e da escrita.

Os avanços nos estudos pedagógicos e linguísticos ampliaram a visão limitada que a escola tinha sobre o ensino-aprendizagem da língua materna. Por isso, paulatinamente mudanças de postura e da didática do professor tornaram-se o foco das atenções dos profissionais da educação. A primeira atitude foi colocar o aluno como sujeito ativo na incessante busca pela construção do conhecimento e o professor como agente mediador nessa construção. Essa foi a deixa para que portas se abrissem, permitindo a entrada de práticas que buscassem o desenvolvimento do aluno nas habilidades não só de leitura e escrita, mas também de expressão oral. Foi nesse contexto em que se começou a ouvir a voz do aluno e, principalmente, a valorização dessa voz no processo de ensinoaprendizagem.

Ainda segundo Antunes (2003), não obstante os avanços conquistados pela escola brasileira nas últimas décadas, alguns equívocos perduram até hoje nas práticas de ensino de muitos professores, os quais continuam reproduzindo práticas tradicionais de seus antigos mestres. Não se calou a voz do aluno, no entanto em muitas escolas as atividades continuam focadas apenas na leitura e produção de textos escritos, enquanto que o oral está reduzido, muitas vezes, a atividades como leitura expressiva $e$ dramatizada, roda de conversa, leitura em voz alta, debates espontâneos e comentários.

A prática de comunicação oral continua ocorrendo em ambientes particulares da vida do aluno por meio dos gêneros discursivos informais. À escola caberia o ensino dos gêneros orais formais, como seu dever prioritário. Outras instituições ajudam no desenvolvimento das competências e habilidades orais quando os seus frequentadores se envolvem em práticas reais de comunicação formal oral, mas não há ensino. É muito comum nas salas de aula, por exemplo, identificarmos em alunos integrantes de uma comunidade das religiões evangélicas o domínio de certos gêneros orais relacionados à instância pública, como a preleção, o sermão expositivo, a palestra, dentre outros. 
Sabemos, então, que a escola não é a única instituição promotora das diversas práticas sociais de uso da língua, pois o sujeito está inserido numa sociedade em que é conduzido, todo tempo, a produzir gêneros discursivos nos mais variados espaços de sua vida pública e particular. No entanto, a escola não pode omitir sua responsabilidade e esperar que seus integrantes adquiram, espontaneamente, domínio da produção dos gêneros discursivos orais formais, já que muitas vezes ainda nos limitamos, nós, professores, ao ensino dos gêneros escritos na sala de aula. Como bem já enfatizavam os Parâmetros Curriculares Nacionais de Língua Portuguesa,

Cabe à escola ensinar o aluno a utilizar a linguagem oral nas diversas situações comunicativas, especialmente nas mais formais: planejamento e realização de entrevistas, debates, seminários, diálogos com autoridades, dramatizações, etc. Trata-se de propor situações didáticas nas quais essas atividades façam sentido de fato, pois seria descabido "treinar" o uso mais formal da fala. A aprendizagem de procedimentos eficazes tanto de fala como de escuta, em contextos mais formais, dificilmente ocorrerá se a escola não tomar para si a tarefa de promovê-la (BRASIL, 1997, p. 27).

Sendo assim, a escola tem como meta contribuir para a apropriação de práticas discursivas, inclusive as do âmbito das instâncias públicas; falta-lhe, contudo, dar mais atenção aos gêneros discursivos orais formais e consolidar estratégias de ensino para que o professor tenha suporte ao realizar seu trabalho no ensino dessa modalidade de texto. A esse respeito, podemos afirmar que nos últimos vinte anos tem sido consenso entre autores brasileiros que discutem sobre o ensino de Língua Portuguesa atribuir aos Parâmetros Curriculares Nacionais (PCNs) a responsabilidade de propagar e incentivar, por meios das orientações, o uso dos gêneros orais e escritos no ensino da língua portuguesa, como pode ser conferido em Araújo e Silva (2016), Bueno e Costa-Hübes (2015) e Leal e Gois (2012).

No final da década de 1990, a preocupação em estruturar o ensino da língua e de revisar práticas tradicionais predominantes justificaram a elaboração dos PCNs, cujo foco estava direcionado à Educação Básica, em um projeto educativo que lutava por métodos mais eficazes. Nos PCNs de Língua Portuguesa (BRASIL, 1997), em especial, é possível verificar uma revisão de conceitos relacionados à linguagem, língua, texto e ensino, a fim de orientar a prática de ensino de português; além da inclusão da língua oral como parte integrante do bloco de conteúdos imprescindíveis ao desenvolvimento das habilidades linguísticas. 
O texto, configurado nos gêneros textuais/discursivos, passou a ser considerado como unidade de ensino e buscou-se instaurar nas salas de aula a análise linguística como prática de reflexão sobre a língua oral e escrita. Um de seus objetivos era permitir que $o$ aluno pudesse, conforme enfatiza esse documento,

[...] expandir o uso da linguagem em instâncias privadas e utilizá-la com eficácia em instâncias públicas, sabendo assumir a palavra e produzir textos - tanto orais como escritos - coerentes, coesos, adequados a seus destinatários, aos objetivos a que se propõem e aos assuntos tratados" (BRASIL, 1997, p. 33).

Em relação à oralidade, os PCNs alertavam sobre a necessidade de garantir atividades sistemáticas de fala, escuta e reflexão sobre a língua oral, enfatizando que isso não significa deixar que as crianças falem, pois não será apenas o falar cotidiano e a exposição do falar alheio que garantem o aprendizado, mas é indispensável que essas atividades estejam adequadas, que consigam desenvolver no aluno o uso da língua oral em contextos públicos de forma cada vez mais competente.

Desde esse período tornou-se um desafio capacitar milhares de professores para que os gêneros discursivos fossem objetos de ensino-aprendizagem na sala de aula. Apesar das limitações e equívocos no decorrer desse processo, os gêneros discursivos têm recebido uma especial atenção, principalmente nos últimos anos, com a realização e divulgação de inúmeras pesquisas na área. O professor de português, consciente de seu papel como mediador da aprendizagem, deve saber que os gêneros discursivos se configuram como práticas de linguagem socialmente construídas ao longo da nossa história e que devem ser, portanto, utilizados também no ensino/reflexão sobre a língua.

Com a Base Nacional Comum Curricular - BNCC (BRASIL, 2017) reforça-se, na área de linguagens, o estudo da língua com foco nos gêneros discursivos, reafirmando o que já preconizavam os PCNs para o ensino de Língua Portuguesa (BRASIL, 1997), como se pode verificar nos excertos abaixo:

Assume-se aqui a perspectiva enunciativo-discursiva de linguagem, já assumida em outros documentos, como os Parâmetros Curriculares Nacionais (PCN), para os quais a linguagem é "uma forma de ação interindividual orientada para uma finalidade específica; um processo de interlocução que se realiza nas práticas sociais existentes numa sociedade, nos distintos momentos de sua história"[...]

O texto ganha centralidade na definição dos conteúdos, habilidades e objetivos, considerado a partir de seu pertencimento a um gênero discursivo que circula em diferentes esferas/campos sociais de atividade/comunicação/uso da linguagem. [...] Ao componente Língua Portuguesa cabe, então, proporcionar aos estudantes experiências que 
contribuam para a ampliação dos letramentos, de forma a possibilitar a participação significativa e crítica nas diversas práticas sociais permeadas/constituídas pela oralidade, pela escrita e por outras linguagens (BRASIL, 2017, p. 65-66).

Pelo que se observa na proposta da BNCC, os vários aspectos da língua são ratificados como fundamentais para o desenvolvimento das habilidades linguísticas que se pretende desenvolver nos estudantes. Dentre eles está a oralidade, que passa a ter maior ênfase no ensino da língua materna, integrando um dos quatro eixos, os quais configuram as práticas de linguagem: Eixo leitura, Eixo produção de textos, Eixo oralidade e Eixo da análise linguística/semiótica. No Eixo oralidade são especificadas somente habilidades que se relacionam com os gêneros discursivos e aos aspectos próprios da modalidade oral, apesar de ela também ser evidenciada nos eixos leitura e produção de textos.

O Eixo oralidade reforça as práticas em que seja possível o aprofundamento do conhecimento e uso da língua oral, o estudo de suas características e das estratégias de fala e escuta nas conversações, bem como as relações entre oralidade e escrita. A especificação desse eixo é de fundamental importância para que os professores focalizem o ensino da língua também no âmbito da oralidade e não o restrinja à escrita, visto que se propõe sistematizar os conhecimentos nas práticas de linguagem e seus respectivos objetos de conhecimento, pautando-se nas habilidades específicas para os alunos da educação básica. Na próxima seção deste artigo, apresentamos parte da pesquisa que realizamos, como diagnóstico sobre competências e habilidades de um gênero discursivo oral, seminário de sala de aula, de alunos de uma turma do oitavo ano do ensino fundamental, em uma escola pública do interior da Bahia, com vista à aplicação, posterior, de uma proposta de intervenção pedagógica para o aperfeiçoamento dessas competências e habilidades.

\section{O diagnóstico do problema em uma sala de aula do ensino fundamental}

A primeira atividade com gêneros discursivos orais na turma do $8^{\circ}$ ano, com vistas à elaboração da proposta de intervenção pedagógica, foi a apresentação de seminários a partir do tema geral Adolescência: participação e cidadania. A escolha dessa atividade deveu-se ao fato de, como indicado no questionário, o seminário fazer parte do cotidiano escolar da turma. Inicialmente, a professora-pesquisadora esclareceu aos alunos que a atividade que fariam a partir daquele momento estava relacionada a um projeto, cuja 
aplicação ocorreria no ano seguinte, quando eles estivessem no $9^{\circ}$ ano. A docente esclareceu que as apresentações precisariam ser gravadas. Os alunos concederam a permissão, através de formulários de prévio consentimento, também assinados pelos pais e/ou responsáveis legais pelos discentes, submetidos e aprovados pelo Comitê de Ética em Pesquisa da Universidade onde a professora realizava o mestrado.

Para iniciar, discutiram um pouco sobre o tema geral do seminário, partindo de questões pré-selecionadas, apresentadas oralmente pela docente. Em seguida, a professora-pesquisadora dividiu a turma em grupos para que apresentassem os seguintes subtemas, indicados por estarem em ano de eleições gerais para a Presidência da República e para o Legislativo Federal: Essa tal política; Política e participação: uma dupla dinâmica; E os jovens, nisso tudo?; Quais as formas de participação?;Postura do Jovem cidadão. Por se tratar de um diagnóstico, os alunos foram informados apenas que deveriam se preocupar com a postura, a não usar gírias, além da necessidade de utilizarem recursos visuais na apresentação, quer fossem cartazes ou apresentação de slides.

O gênero discursivo seminário, como um assunto a ser estudado, não foi abordado nesse período, propositalmente, pois a intenção da pesquisadora era não influenciar muito o desempenho dos sujeitos da pesquisa, quanto à apresentação do gênero, a fim de avaliar o conhecimento prévio dos alunos. Segundo Schneuwly e Dolz (2011, p. 184), a exposição oral, como a exemplo do seminário, vem de longa tradição escolar, mas sem um trabalho didático efetivo, sem que a construção da linguagem seja objeto de atividades na sala de aula e sem a adoção de estratégias ou procedimentos para a avaliação. No questionário aplicado previamente aos alunos, o seminário foi apontado por alguns como uma das atividades recorrentes na sala de aula, por diversas disciplinas, como já era de conhecimento da professora-pesquisadora, por sua experiência cotidiana na escola. Tais seminários têm como objetivo somente possibilitar aos alunos estudar e discutir sobre determinados conteúdos curriculares, sem reflexão sobre o gênero discursivo em si mesmo.

Algumas aulas foram dedicadas ao estudo dos subtemas pelos grupos e para a organização dos seminários. A professora-pesquisadora fez um breve tutorial sobre como produzir um slide pelo Power Point, a fim de estimular seu uso nas exposições. Por ser uma atividade que seria gravada, houve preocupação e nervosismo por parte dos alunos. No primeiro dia das apresentações, era comum vê-los tentando decorar a parte 
que Ihes cabia para falar ao público (colegas). Por duas vezes foram obrigados a desistir das apresentações nas datas marcadas, devido à indisponibilidade de projetor para exibir os slides produzidos pelos alunos. Por essa razão, no dia em que conseguiram realizar os seminários apenas duas equipes se apresentaram.

De acordo com Schneuwly e Dolz (2011, p. 186), a exposição oral em sala de aula reúne o aluno que produz uma exposição e um público - colegas para quem ele se dirige, agrupados para ouvi-lo, e possibilita aprender algo sobre um tema, adquirir ou enriquecer seu conhecimento. Para alcançar seu objetivo ele precisará se organizar em vários aspectos, seja na ordenação interna da exposição ou dos elementos linguísticos. Por isso, observamos algumas das características desse gênero nas apresentações dos participantes, conforme pesquisas de Schneuwly e Dolz (2011 p. 187-190), sobre os conteúdos do gênero seminário, elencadas no quadro abaixo:

Quadro 1 - Características do gênero discursivo seminário

\begin{tabular}{|l|l|}
\hline \multicolumn{2}{|c|}{ CARACTERÍSTICAS DO SEMINÁRIO } \\
\hline Organização interna da exposição & Características linguísticas e textuais \\
\hline Fase de abertura e introdução ao tema & Coesão temática \\
\hline Apresentação do plano da exposição & Desenvolvimento das conclusões resumidas \\
\hline Desenvolvimento e encadeamento dos diferentes temas & Introdução de exemplos \\
\hline Recapitulação e síntese & Reformulações \\
\hline Conclusão & Sinalização do texto \\
\hline Encerramento & \\
\hline
\end{tabular}

Fonte: elaborado pela pesquisadora, a partir de Schneuwly e Dolz (2011, p. 187-190).

A fase de abertura e introdução ao tema refere-se ao momento inicial em que "o expositor toma contato com o auditório, saúda-o, legitima sua fala [...]" (SCHNEUWLY; DOLZ, 2011, p. 187). No caso da sala de aula, este pode ser o momento em que um dos alunos serve de mediador entre os componentes do grupo, a fim de situar o público ouvinte, seus colegas. Nos dois grupos de apresentação do seminário houve a mediação inicial de um dos participantes, que apresentou o assunto e os componentes de seu grupo, mas não apontou a motivação e nem declarou os objetivos da exposição, como podemos observar pelas transcrições de parte dos seminários, como exemplos, abaixo:

1. Grupo $01^{5}$

Aluno 1A: Bom dia [...] a gente:: ((risos))

Aluno 1B: Bom dia [...] a gen:te vai apresentar sobre a tal política [...] é: [...] eu sou $L[. .$.$] ((apontando para os componentes da equipe)) C...D... e.: V... e.: a$

\footnotetext{
${ }^{5}$ Trouxemos, na transcrição, apenas a inicial dos nomes dos alunos, para preservar-lhes a identidade. Para a transcrição, seguimos as normas e procedimentos utilizados para transcrição de falas, comuns à Linguística Textual ou à Análise da Conversação.
} 
gente vai explicar pra vocês sobre a política em geral e sobre: a gente... jovem se envolver na política.

Grupo 02

Aluno 2A: Bom dia: pessoal [...] eu sou a $E$ [...] e a gente vai apresentar um pouquinho sobre política e [...] dina:mica [...] e.:.: [...] participação ((aponta para apresentar os componentes da equipe)) $A$ [...] e.: L [...] também [...] aí ela vai começar [...]

Essa mediação, no entanto, ficou limitada ao início da apresentação. Depois, as trocas de turnos de fala ocorreram pela indicação gestual de um colega ao outro ou por meio de sussurros. Nenhum dos grupos apresentou maiores explicações sobre como eles procederiam às apresentações; além de não introduzirem a fala do colega. Isso só ocorria por meio de gestos com a mão ou indicação com a cabeça. Sendo assim, não houve a apresentação do plano da exposição que, para Schneuwly e Dolz (2011, p. 188) é o momento de esclarecer sobre o produto e o procedimento, que se dá pela enumeração de ideias ou de subtemas. Como foi possível verificar no exemplo 1, o grupo 01 apenas apresentou de forma breve os dois tópicos do assunto a serem abordados: a política em geral e sobre o jovem se envolver na política.

Em relação ao desenvo/vimento e encadeamento de diferentes temas, os autores afirmam que a quantidade de temas deve corresponder ao que foi anunciado no plano. Nesse caso, somente o grupo 01 se aproximou dessa etapa, pois conseguiu organizar a exposição dos temas na ordem que planejou, apesar de não sinalizar a progressão do tema. Já o grupo 22 , em momento algum apresentou os tópicos que seriam explanados e não houve planejamento no encadeamento das falas, um aluno parava e o outro continuava, sem fazer ligação entre os tópicos.

A fase de recapitulação e síntese em um seminário é "importante não só porque permite retomar os principais pontos da exposição, como também porque constitui uma fase de transição entre a exposição propriamente dita e as duas etapas de conclusão" (SCHNEWLY; DOLZ, 2011, p. 188). Nenhuma das equipes recapitulou ou sintetizou o que foi dito anteriormente. Nos últimos momentos, eles falaram ininterruptamente e pararam de forma abrupta. Já a conclusão, que pode ocorrer por meio de uma mensagem final ou dar início a um debate, pôde ser identificado nas duas equipes. Nas apresentações em análise, só houve a mensagem final, como podemos perceber pelo exemplo 2, abaixo:

\section{Grupo 01}

Aluno 1B: todos nós somos [...] é:: culpados por isso [...] por vender [...] por vem-dermos nossos votos é o que nós não devemos fazer [...] então [...] vocês que estão por volta da faixa dos 16 anos vai fazer o primeiro voto [...]/ 
Pensem bem porque é um voto desperdiçado isso não afeta vocês... porque: pelo contrário [...] isso aumenta a renda de vida deles e diminui a sua... você vai ficar doente e: não vai ter um hospital bom pra você [...] pra você se tratar porque você deu seu voto perdido [...] então é só isso [...] obrigado

Grupo 02

Aluno 2C: a eleição é em::[...] 2018? ((confirmando com os outros componentes do grupo)) a eleição tá vindo [...] então temos que a::ana:: analisar ((risos)) temos que analisar quem a gente vai escolher [...] para a gente podermos ter um futuro melhor [...] só isso [...]

O encerramento foi feito de forma abrupta pelas duas equipes, utilizando-se apenas as expressões: $E$ isso e $E$ só isso... Obrigado, como se verifica no exemplo 2, sem que fosse aberto um espaço para questionamento dos colegas ou para suscitar um debate sobre o tema. Todos os alunos sentaram em seus lugares imediatamente ao término da última fala, como se já tivessem realizado a atividade.

Quanto às características linguísticas e textuais, existem operações essenciais na produção de uma exposição oral, apontadas por Schneuwly e Dolz (2011, p. 189, 190), das quais analisaremos a coesão temática, a sinalização do texto, a introdução de exemplos e reformulações. A coesão temática assegura a articulação entre os temas da exposição, a fim de orientar o público quanto à sequência das ideias. Sobre esse aspecto, nenhuma das equipes teve a preocupação de indicar os tópicos subsequentes. Em relação à sinalização do texto, que envolve explicações das descrições, conclusões resumidas e uso de marcadores de estruturação do discurso, somente em poucos momentos houve a presença de algumas dessas operações, a exemplo da expressão $E$ esse remédio de AIDS, em que o aluno $2 \mathrm{C}$ utiliza o pronome demonstrativo para retomar e concluir a ideia do colega, como verificamos nos trechos a seguir:

\section{Grupo 2}

Aluno 2A: [...] existe um movimento que ajuda essas pessoas que têm AIDS a ter... o.: remédio $n$ hora que faltar e tal ((aponta para a colega continuar))

Aluno 2C:E esse remédio de AIDS [...] ele é:: é um dever que a políti [...] que os políticos tem [...]

Grupo 01

Aluno 1A: [...] você tem que entender as intenções dele [...] pra não Ihe prejudicar no futuro [...] como [...] é:: a explicação antes disse [...] porque se a gente não conhecermos o político que estamos elegendo... como vamos saber se ele vai fazer boas obras em nossa cidade [...] estado [...] ou país?

Apesar de não ter sido recorrente, na fala do Aluno $1 \mathrm{~A}$ há também a retomada de uma ideia já apresentada, como observamos na expressão como...é:: a explicação antes disse, reforçando sua posição sobre o assunto e dando sequência ao tema; já o Aluno $2 \mathrm{C}$ utiliza-se da explicação de uma descrição anterior para dar continuidade ao mesmo tema. As operações de sinalização são importantes para indicar, no decorrer da 
exposição, as temáticas que se pretendem abordar, para indicar as fases da exposição, 0 que, infelizmente, não foi identificado nas apresentações. A introdução de exemplos, por outro lado, foi realizada pelas duas equipes, como se verifica nos trechos abaixo:

\section{Grupo 01}

Aluno 1A: Muitas pessoas acham que política é simplesmente reunir vários é:: setores... governadores:: é:: prefeitos:: vereadores:: é:: presidentes:: e eles discutirem entre si... mas não é bem assim... tem um::- eu esqueci o nome dele agora - tem um:: um:: determinado momento em cada situação que eles dão direito a população a ir em uma reunião na câmara de vereadores... aqui em Ipiaú também existe isso... para eles ir verem a:: as:: ações:: que os políticos querem fazer [...]

Aluno 1A: Se você vai numa lanchonete e você compra um produto lá que não Ihe agradou você e você vai reclamar ao gerente ou ao funcionário que:: que:: forneceu o produto... você já está fazendo a política [...]

Aluno 1A: [...] os políticos procuram muito essas pessoas novas pra fazerem a cabeça... como:: por exemplo... trabalhar em boca de urna ((sinaliza aspas com as mãos))

Grupo 02

Aluno 2C: [...] nós temos o direito a:: a:: aos remédios que o posto ou médico oferece se não tiver condições... aí sim...a gente pode decorre pra outro lugar [...] pra conseguir fazer [...] é:: que nem minha tia mesmo... ela foi fazer uma cirurgia:: aí:: ela não tem condição [...]

Nos trechos apresentados, verifica-se a presença de exemplos tanto explicativos como ilustrativos, para esclarecer ou legitimar os discursos, como as expressões aqui em Ipiaú também existe isso... e como:: por exemplo..., do Aluno 1A; e também a expressão que nem minha tia mesmo, do Aluno $2 \mathrm{C}$. Quanto às reformulações que, segundo Schneuwly e Dolz (2011, p. 190), servem como paráfrases para esclarecer termos difíceis ou novos, foram realizadas na intenção de esclarecer a leitura dos textos dos slides (Aluno $1 \mathrm{~A}$ ) ou para explicar melhor o discurso emitido por outro componente (Aluno 2C), conforme percebemos no exemplo 05 , a seguir:

\section{Grupo 01}

Aluno 1A: ou seja [...] é importante a gente conhecer a política an:tes de elegermos um político porque... muitas pessoas acham que política é simplesmente você escolher seu candidato [...] ir lá [...] votar [...] na urna [...] e:: está tudo certo [...]

Aluno 1A: ou seja [...] a política [...] é:: [...] como diz esse homem [...] é:: interesse de todos [...] nós todos nós somos animais políticos, por que?... porque todos nós temos um envolvimento com a política ((olhando para a câmera)) Grupo 02

Aluno 2A: [...] ou seja existe um movimento que ajuda essas pessoas que têm AIDS a ter [...] o.: remédio na hora que faltar e tal ((aponta para a colega continuar))

Nas apresentações, esses conteúdos relacionados ao gênero seminário puderam ser identificados, mesmo que em menor ocorrência, no desempenho de alguns dos 
componentes das equipes. Houve maior participação do aluno $1 \mathrm{~A}$ e $2 \mathrm{C}$. Os outros apresentadores se limitaram à leitura dos slides ou dos textos no caderno e no celular, sem emitirem comentários a respeito do tema. Assim, não conseguimos identificar nas apresentações desses últimos alunos os aspectos linguísticos e de organização interna da exposição/seminário, aqui analisados. Para melhor identificação dos processos linguísticos e extralinguísticos na prática do seminário das equipes, a pesquisadora elaborou um quadro em que identifica com um SIM as ocorrências, NÃO para ausência de ocorrências e EM PARTE quando os alunos não executaram por completo o processo.

Quadro 2 - Comparativo das equipes na execução do seminário

\begin{tabular}{|l|c|c|}
\hline \multicolumn{1}{|c|}{ Organização interna da exposição } & Grupo 01 & Grupo 02 \\
\hline Fase de introdução ao tema & & \\
\hline Apresentação do plano da exposição & SIM & SIM \\
\hline Desenvolvimento e encadeamento dos diferentes temas & NÃO & NÃO \\
\hline Recapitulação e síntese & EM PARTE & NÃO \\
\hline Conclusão & NÃO & NÃO \\
\hline Encerramento & EM PARTE & EM PARTE \\
\hline & NÃO & NÃO \\
\hline & Grupo 01 & Grupo 02 \\
\hline Coesão temática NÁrsticas linguísticas & NÃO & NÃO \\
\hline Sinalização do texto & NÃO & EM PARTE \\
\hline Desenvolvimento das conclusões resumidas & NÃO \\
\hline Introdução de exemplos & SIM & SIM \\
\hline Reformulaç̃̃es & SIM & SIM \\
\hline
\end{tabular}

Fonte: elaborado pela pesquisadora com base nas análises dos dados coletados.

O quadro 02 aponta que cinco dos onze conteúdos relacionados ao seminário não foram identificados nas apresentações. Apenas três deles foram realizados pelos alunos na íntegra. Os outros três, somente em parte. Dos questionamentos, suscitados a princípio, obtivemos a seguinte constatação: existem características/ conteúdos como a introdução ao tema, a introdução de exemplos e reformulações, que somente alguns alunos conseguem utilizar na prática do gênero discursivo seminário. Por isso, os conteúdos dos gêneros discursivos orais, sua estrutura, modos de funcionamento e características linguísticas e textuais precisam ser formalmente ensinados, para que sejam realizados com constância e conscientemente.

Há que se considerar que avaliamos somente as características de um único gênero discursivo oral, mas só por esse breve diagnóstico pudemos perceber que os alunos têm muito o que aprender com o ensino formal de gêneros discursivos orais da 
instância pública. Cabe ao professor de português, com maior responsabilidade, o planejamento cuidadoso e a prática constante desses gêneros em suas aulas. $O$ trabalho permanente e com uma maior variedade de gêneros discursivos orais possibilitará aos discentes o domínio competente dessa modalidade de texto. Torna-se importante, contudo, que o professor envolva todos os alunos no processo, não apenas uns poucos representantes de equipes.

\section{Considerações Finais}

O tratamento que a BNCC (BRASIL, 2017) almeja dar às práticas orais está sistematizado nas seguintes ações: reflexão sobre as condições de produção dos textos orais, compreensão de textos orais, produção de textos orais, compreensão dos efeitos de sentido provocados pelos usos de recursos linguísticos e multissemióticos em textos pertencentes a diversos gêneros, e na relação entre fala e escrita. Além da organização dessas práticas de linguagem por campo de atuação, como o campo da vida cotidiana, da vida pública, das práticas de estudo e pesquisa, do jornalístico/midiático e do artísticoliterário. Tal perspectiva, de certa forma, impõe a presença de gêneros discursivos na sala de aula, objetos de estudo, inclusive para as análises linguísticas a serem concretizadas nas aulas de Língua Portuguesa.

Ainda sobre a oralidade, a BNCC (BRASIL, 2017) sinaliza que o estudo de tal modalidade possibilita ao aluno do ensino fundamental a interação e participação em discussões orais; a reflexão sobre o funcionamento do discurso oral, em que se permite analisar os elementos que constituem o discurso nas diversas práticas de uso da língua; estudo da relação entre o texto oral e o escrito; formação de estratégias de escuta de textos orais, cujo foco está na elaboração de procedimentos para a técnica do ouvir/escutar de forma que se possa registrar informações no decorrer do processo; além da produção de textos orais, em práticas autênticas de comunicação e interação.

Sendo assim, a BNCC (BRASIL, 2017) nos apresenta uma sequência de habilidades que podem ser desenvolvidas gradativamente em relação à oralidade e aos elementos específicos do texto oral, assim como já preconizavam os PCNs (BRASIL, 1997). Dessa forma, o que fica evidente ao longo das duas últimas décadas é que o foco no ensino da oralidade vem tomando fôlego, ao menos nesses referenciais teóricos e, atualmente, pensar em um trabalho com o oral na mesma intensidade em que se trabalha com a escrita é o que é desejável. 
A análise dos dados sobre o gênero discursivo seminário escolar, como diagnóstico apresentado neste artigo, permitiu concluir que cinco dos onze conteúdos relacionados ao seminário não foram identificados nas apresentações dos discentes, apenas três deles foram demonstrados pelos alunos na íntegra e os outros três apenas parcialmente. Dos questionamentos, suscitados a princípio, obtivemos a seguinte constatação: existem características/ conteúdos que somente alguns alunos conseguem demonstrar, sobre o gênero discursivo seminário, devido à sua prática mais frequente. Por isso, os conteúdos dos gêneros discursivos orais, sua estrutura, modos de funcionamento e características linguísticas e textuais precisam ser formalmente ensinados, para que sejam realizados com constância e conscientemente, conforme já prescritos nos documentos oficiais que direcionam o ensino de Língua Portuguesa na educação básica, como consta da Base Nacional Comum Curricular (BRASIL, 2017).

Os documentos oficiais que direcionam o ensino de Língua Portuguesa na educação básica reconhecem a existência de regularidades nos aspectos do texto oral, que podem ser sistematizados, analisados e avaliados no processo ensino-aprendizagem. Portanto, torna-se necessário que nós, professores, conscientes dessa realidade, fortaleçamos a presença da oralidade em nossas aulas, por meio dos gêneros discursivos orais. Começar por um trabalho de avaliação das habilidades prévias dos alunos, como demonstramos neste artigo, pode ser o primeiro passo acertado nessa empreitada.

\section{Referências}

ANTUNES, Irandé. Aula de português. encontro e interação. São Paulo: Parábola, 2003. ARAÚJO, Denise Lino de; SILVA, Williany Miranda da. Oralidade em foco: conceitos, descrição e experiências de ensino. Campinas: Pontes, 2016.

BRASIL. Base nacional comum curricular (BNCC): educação é a base. Brasíla, DF: MEC /CONSED/UNDIME, 2017.

BRASIL. Secretaria de Educação Fundamental. Parâmetros curriculares nacionais: língua portuguesa. Brasília: SEF, 1997.

BUENO, Luzia; COSTA-HÜBES, Terezina da Conceição (org.). Gêneros orais no ensino. Campinas: Mercado de Letras, 2015.

LEAL, T. F.; GOIS, S. (org.). A oralidade na escola: a investigação do trabalho docente como foco de reflexão. Belo Horizonte: Autêntica, 2012. 
Silva, C. S.; Santos, A. P.; Heine, M. B. L.

MARCUSCHI, Luíz Antônio. Da fala para a escrita: atividades de retextualização. 10. ed. São Paulo: Cortez, 2010.

ONG, Walter. Oralidade e cultura escrita. Campinas: Papirus, 1998.

SCHNEUWLY, Bernard; DOLZ, Joaquim. Gêneros orais e escritos na escola. 3. ed. São Paulo: Mercado de Letras, 2011.

SILVA, Cinara Sousa da. Conteúdos da oralidade: uma proposta de intervenção pedagógica com o gênero discursivo seminário escolar. 2019. 223 f. Dissertação (Mestrado Profissional em Letras) - Departamento de Ciências Humanas, Universidade do Estado da Bahia, Santo Antônio de Jesus, 2019.

ZUMTHOR, Paul. A letra e a voz: a literatura medieval. São Paulo: Companhia das Letras, 1993. 